\title{
Taguchi based fuzzy logic model for optimisation and prediction of surface roughness during AWJM of DRCUFP composites
}

\author{
Raviraj Shetty(D) and Adithya Hegde* (D) \\ Department of Mechanical and Manufacturing Engineering, Manipal Institute of Technology, Manipal Academy of Higher \\ Education Manipal 571604, Karnataka, India
}

Received: 27 July 2021 / Accepted: 13 October 2021

\begin{abstract}
From last two decades, plant fiber reinforced polymer/polyester composites have been effectively used in structural and automotive applications. Researchers and manufacturers are looking forward for an effective utilization of these composites. However, despite the outstanding properties in terms of load bearing capacity and environmental sustainability of plant fibers the uptake of these composites are limited due to its poor machinability characteristics. Hence in this paper, Taguchi based fuzzy logic model for the optimization and prediction of process output variable such as surface roughness during Abrasive Water Jet Machining (AWJM) of new class of plant fiber reinforced polyester composites i.e., Discontinuously Reinforced Caryota Urens Fiber Polyester (DRCUFP) composites has been explored. Initially machining experiments has been carried out using $\mathrm{L}_{27}$ orthogonal array obtained from Taguchi Design of Experiments (TDOE). Finally, Taguchi based fuzzy logic model has been developed for optimisation and prediction of surface roughness. From the extensive experimentation using TDOE it was observed that the optimum cutting conditions for obtaining minimum surface roughness value, water pressure (A): 300 bar, traverse speed (B): $50 \mathrm{~mm}$, stand of distance: $1 \mathrm{~mm}$, abrasive flow rate: $12 \mathrm{~g} / \mathrm{s}$, depth of cut (C): $5 \mathrm{~mm}$ and Abrasive Size:200 microns. Further from FLM, it is observed that minimum water pressure (A): 100 bar, traverse speed (B): $50 \mathrm{~mm}$, stand of distance: $1 \mathrm{~mm}$, abrasive flow rate: $8 \mathrm{~g} / \mathrm{s}$, depth of cut $(\mathrm{C}): 5 \mathrm{~mm}$ and abrasive size:100 microns gave higher surface roughness values (3.47 microns) than that at maximum water pressure (A): 300 bar, traverse speed (B): $150 \mathrm{~mm}$, stand of distance: $4 \mathrm{~mm}$, abrasive flow rate: $12 \mathrm{~g} / \mathrm{s}$, depth of cut (C): $15 \mathrm{~mm}$ and abrasive size:200 microns the surface roughness values (3.25 microns).
\end{abstract}

Keywords: DRCUFP composites / AWJM / surface roughness / TDOE / fuzzy logic model (FLM)

\section{Introduction}

Around 3000 years ago Egyptians made use of the concept of plant fiber reinforced composites (PFRC) using straw reinforced clay as construction materials [1]. It has been revealed that plant fibers possess a unique mechanical property, easy manufacturability and can be subjected to surface treatment process for improvising its properties [2-4]. Today PFRC has been widely used as non-structural components for automotive and building industry [5-9] suggested that cost and ecological awareness has driven plant fiber composites a huge demand in wide variety of applications [10-18] carried out research on application of cellulose based natural fibers such as jute, flax and hemp as an alternative to glass fiber in composites. Ramesh et al. [19] suggested that less weight, low cost, biodegradability and good strength has made plant fibers a substitute for other materials.

\footnotetext{
* e-mail: adithya.hegde@learner.manipal.edu
}

Raviraj Shetty et al. [20] carried out research on processing, mechanical characterization and its tribological study on DRCUFP composites. They suggested that 20 fiber vol.\% DRCUFP composite had excellent load bearing capacity and it's bending properties [21] developed Discontinuously Reinforced Sisal Fiber Polyester (DRSFP) composite laminates. In their work mechanical characterization and machinability study on DRSFP such as surface roughness and de-lamination during drilling based on design of experiments has been investigated. Shetty et al. [22,23] and [24] explored areas related to application of Design of Experiments in metal cutting operations. However, high thermal distortion, poor machining versatility, more stress, poor surface finish and delamination occurring during machining of these plant fiber composites during conventional machining has led Abrasive Waterjet Cutting [AWJC] an alternate manufacturing technology for machining of metals and materials [25-30]. Chithirai et al. [31,32] made use of statistical approach during AWJ machining for various metals such as granite, Stainless steel and Cast Iron. Shirpurkar et al. [33], Ravindra et al. [34] 

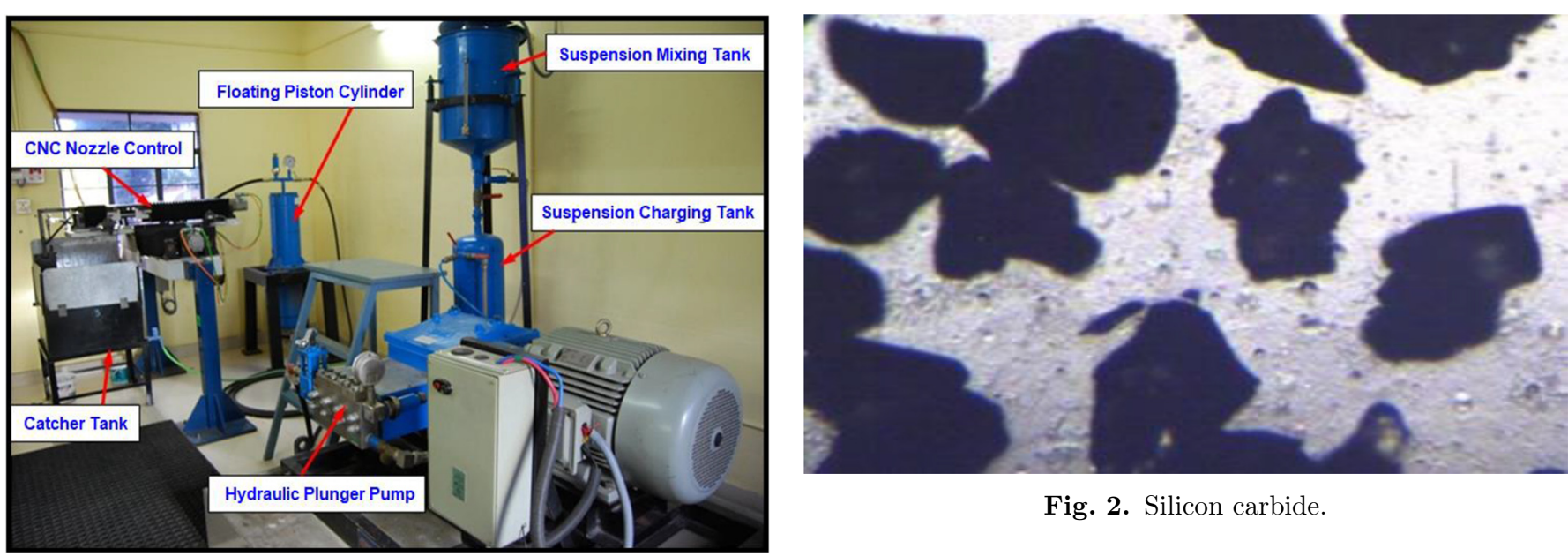

Fig. 2. Silicon carbide.

Fig. 1. Experimental setup.

Table 1. Specifications of abrasive water machining.

\begin{tabular}{|c|c|c|}
\hline Item & Description & Supplier \\
\hline Hydraulic Plunger Pump & $\begin{array}{l}\text { Triplex reciprocating Pump, Direct driven, } \\
\text { Power-30 KW, Discharge - } 16 \text { ltr } / \text { min, Delivery } \\
\text { Pressure - } 60 \text { MPA }\end{array}$ & $\begin{array}{l}\text { GOMA Engg. Pvt, Ltd, } \\
\text { Mumbai, India }\end{array}$ \\
\hline $\begin{array}{l}\text { Floating Piston Cylinder, } \\
\text { Suspension Charging/storage } \\
\text { tank, Air Compressor }\end{array}$ & $\begin{array}{l}10 \text { ltr capacity, } 50 \text { ltr capacity, ELGI make, } 1 \mathrm{HP} \text {, } \\
45 \text { liter capacity, } \\
\text { Delivery Pressure - } 12 \text { bar }\end{array}$ & \\
\hline Nozzles & $\begin{array}{l}\text { SS } / \text { TC materials, Exit Diameter }-0.8 \text { and } \\
1.0 \mathrm{~mm}\end{array}$ & \\
\hline $\begin{array}{l}\text { Suspension mixing tank, } \\
\text { Catcher tank }\end{array}$ & 100liter capacity, $600 \times 600 \times 300 \mathrm{~mm}$ & $\begin{array}{l}\text { Designed and fabricated at } \\
\text { Institution Workshop }\end{array}$ \\
\hline $\begin{array}{l}\text { CNC System for nozzle } \\
\text { movement }\end{array}$ & Two axis control, $\mathrm{X}=450 \mathrm{~mm}, \mathrm{Y}=450 \mathrm{~mm}$ & $\begin{array}{l}\text { Texcel Marketing } \\
\text { Corporation and Microtech } \\
\text { Exports, Banglore, India }\end{array}$ \\
\hline
\end{tabular}

suggested that fuzzy logic can be applied successfully to predict process output variables and can be effectively used for identifying the optimum cutting parameters and preventing time consuming experiments. But research on plant fibre reinforced composites is few.Hence optimization and prediction of surface roughness during AWJM of DRCUFP composites using Taguchi based fuzzy logic model has been investigated in this work.

\section{Methods and materials}

The machining tests were carried out in Abrasive Water machining (Fig. 1). The specifications of Abrasive water machining are shown in Table 1 . The abrasive materials used in the present research was silicon carbide which is shown in Figure 2. Sieve analysis was carried out to estimate the average particle size and to know the particle size distribution of silicon carbide abrasive grains. Table 2 shows the properties of silicon carbide abrasive grains used in this experimentation.
The materials used was 20 vol.\% Caryota Urens fibers having diameter of 8 microns and thickness of $0.2 \mathrm{~mm}$ reinforced with polyester resin of density of $1.1 \mathrm{~g} / \mathrm{cm}^{3}$ and viscosity of 700 Centipoise as the matrix material manufactured by stir casting technique. Table 3 shows the mechanical properties of DRCUP composites. Figure 4 shows the SEM image of DRCUP composites. Figure 5 shows the Talysurf Surtronic $3 \pm$ surface roughness measurement tester used for analyzing of machined surface under different cutting conditions.

\subsection{TDOE}

Taguchi techniques one of the methodology based on design of experiment that has been widely used in manufacturing, metal cutting and engineering applications. The experimentation is carried out using smaller the better characteristics obtained from Taguchi's $\mathrm{L}_{27}\left(3^{13}\right)$ orthogonal array. Table 4 shows the Levels and Factors used in this experimentation. 
Table 2. Properties of silicon carbide abrasive grains.

\begin{tabular}{ll}
\hline Feature & Silicon Carbide \\
\hline General Description & $\begin{array}{l}\text { Solid Granules, Inert to most } \\
\text { chemicals, High strength and } \\
\text { thermal shock resistant, High }\end{array}$ \\
& thermal conductivity \\
Chemical Analysis & $\mathrm{SiC}: 98.54 \%$, \\
& $\mathrm{Free} \mathrm{C}: 0.26 \%$, \\
& $\mathrm{Si} \pm \mathrm{SiO}: 2.68 \%$, \\
& $\mathrm{Fe}_{2} \mathrm{O}_{3}: 0.24 \%$, \\
$\mathrm{Al}_{2} \mathrm{O}_{3}: 0.20 \%$ \\
Colour & $\mathrm{Black}_{\mathrm{G}} \mathrm{Green}$ \\
Particle Shape & $\mathrm{Sharp}_{\text {irregular }}$ \\
Hardness & 9.5 on Mohs Scale \\
Density & $3.22 \mathrm{~g} / \mathrm{cm}^{3}$ \\
Melting point & $2730{ }^{\circ} \mathrm{C}$ \\
Solubility & $\mathrm{Insoluble}$ \\
Coordination geometry & Tetrahedral \\
\hline
\end{tabular}

Table 3. Mechanical properties of DRCUFP composites (Raviraj Shetty et al., 2018).

\begin{tabular}{ll}
\hline Fiber $(\mathrm{Vol} \%)$ & 20 \\
\hline Density $\left(\mathrm{gm} / \mathrm{cm}^{3}\right)$ & $1.3 \pm 0.5$ \\
Vickers Hardness $\left(\mathrm{H}_{\mathrm{v}}\right)$ & $27.3 \pm 0.5$ \\
Young's Modulus $(\mathrm{Gpa})$ & $8.3 \pm 0.25$ \\
Tensile strength at break (Mpa) & $355.6 \pm 0.2$ \\
Flexural Strength (Mpa) & $78.87 \pm 2.5$ \\
Interlaminar Shear Strength (Mpa) & $13.13 \pm 0.3$ \\
\hline
\end{tabular}

$$
\frac{S}{N}=-10 \log \frac{1}{n}\left(\sum y^{2}\right)
$$

where $n$ is the number of observations, and $\mathrm{y}$ is the observed data.

\subsection{Fuzzy logic model}

In metal cutting industries mathematical and empirical modelling developed for predicting machining parameters became very complicated and time consuming. Hence fuzzy logic became a very effective tool to solve incomplete and imprecise information in various engineering fields. Fuzzy logic mainly deals with mathematical theory and probability theory. Fuzzy logic variables are tested with IF-THEN rules. The fuzzy decision making unit is shown in Figure 6.

In this paper, typical fuzzy logic model has been successfully used to analyse the surface roughness during machining of Ti-6Al-4V under MQL condition. Figure 7 demonstrates the factors used for predicting the surface

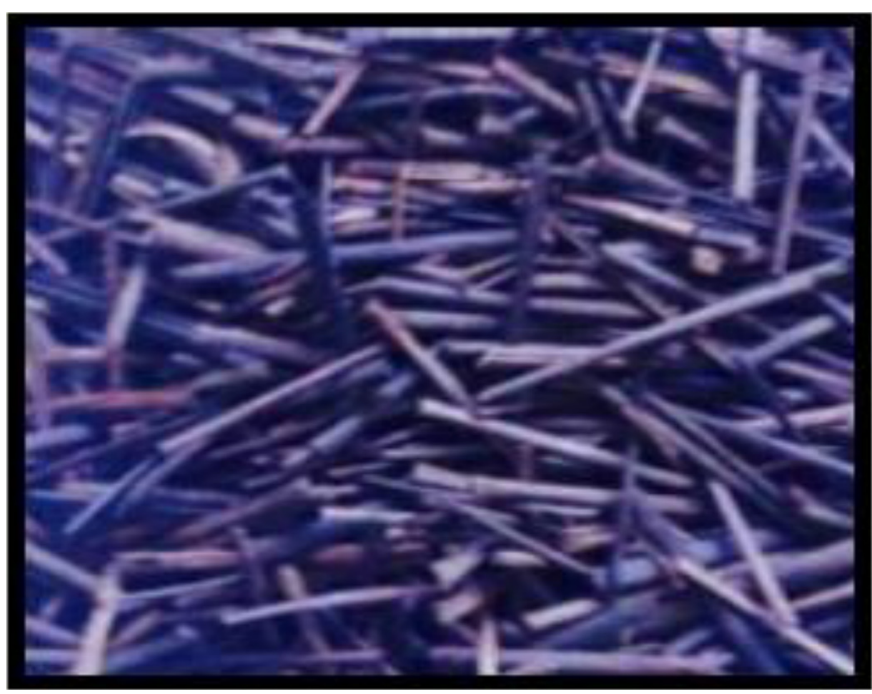

Fig. 3. Caryota urens fibers [19].

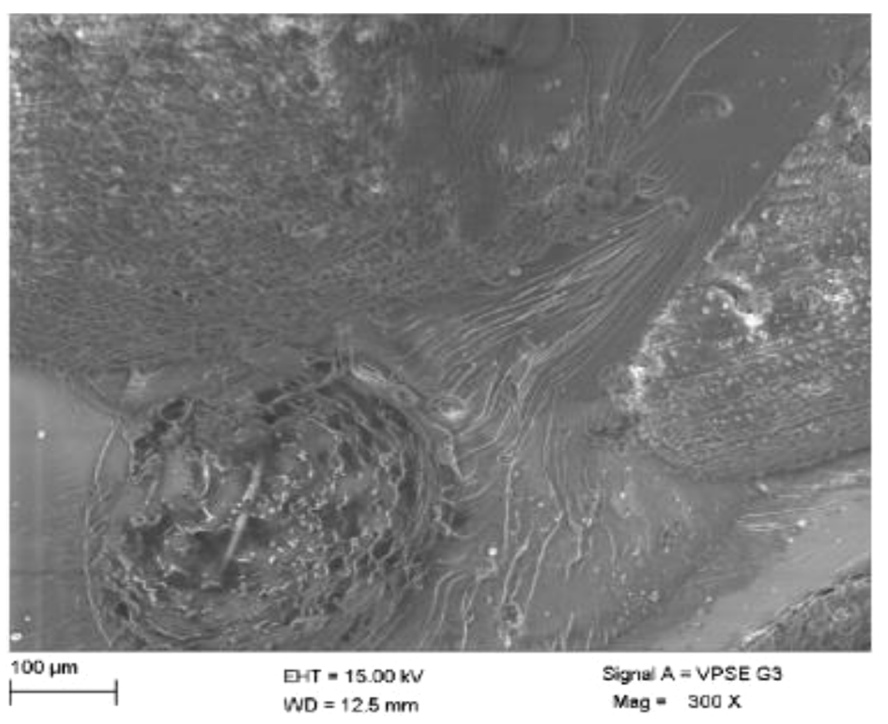

Fig. 4. SEM image of DRCUFP composites.

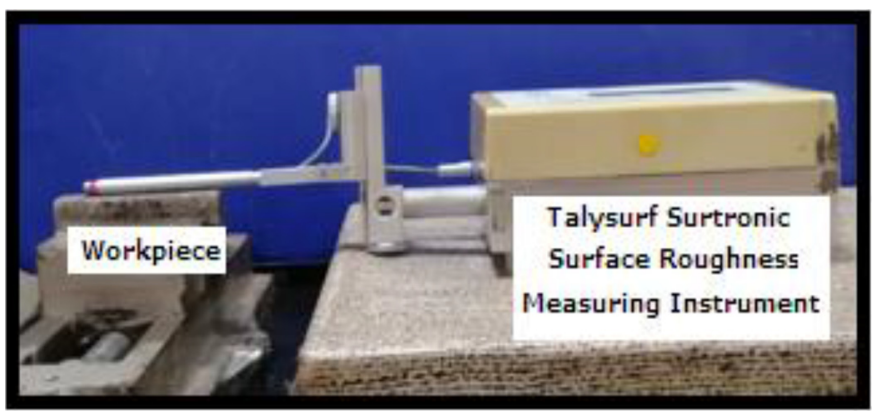

Fig. 5. Surface roughness measurement.

roughness (microns) under different cutting conditions as information parameters. Table 5 shows the fuzzy design matrix of input and output parameters selected for experimentation. 
Table 4. Levels and factors.

\begin{tabular}{llllll}
\hline Sl. No. & Symbols & Variable parameters & Level 1 & Level 2 & Level 3 \\
\hline 1 & A & Water Pressure (bar) & 100 & 200 & 300 \\
2 & B & Traverse Speed (mm/min) & 50 & 100 & 150 \\
3 & C & Stand off distance (mm) & 1 & 3 & 4 \\
4 & D & Abrasive Flow rate (gm/s) & 8 & 10 & 12 \\
5 & E & Depth of Cut (mm) & 5 & 10 & 15 \\
6 & F & Abrasive Size (microns) & 100 & 150 & 200 \\
\hline
\end{tabular}

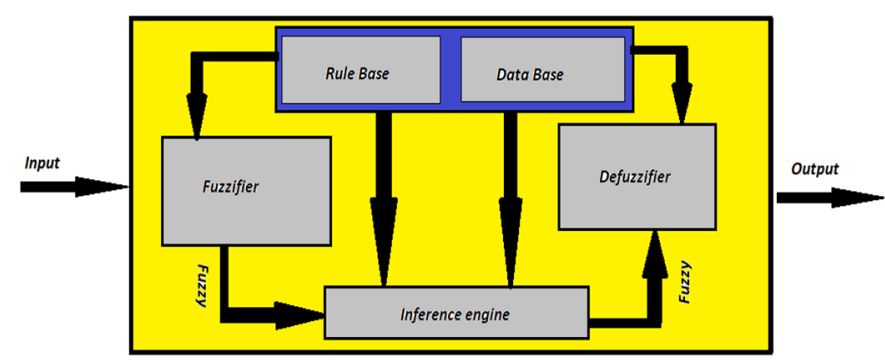

Fig. 6. Fuzzy decision making unit.

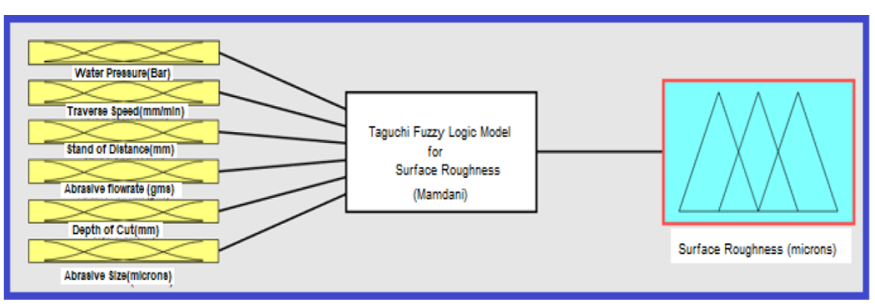

Fig. 7. Fuzzy inference system.

The fuzzy standards were produced by TDOE. Linguistic factors like low, medium, and high are utilized for input parameters such aswater pressure, traverse speed, stand of distance, abrasive flow rate, abrasive size and output parameter, i.e., surface roughness are shown in Table 5. Membership functions of input and output parameters are presented in Figures 8-14. Mamdani fuzzy inference system has been used to find the better accuracy of output of the i.e., surface roughness during AWJM of DRCUFP composites. Seven membership functions have been selected for the output i.e., extremely low, very low, low, medium, high, very high and extremely high as shown in Figure 5.

\section{Results and discussions}

Discontinuously Reinforced Caryota Urens Fiber Polyester (DRCUFP) composites due its anisotropic behaviour and unusual machinability responses such as fiber pullout, delamination and poor surface finish has made to introduce Taguchi based fuzzy logic model for optimisation and prediction of surface roughness during AWJM of DRCUFP composites.

\subsection{Effect of process parameters on surface roughness using TDOE}

The data means of main effects plot obtained from TDOE was to examine the effects of selected set of process input parameters significantly influencing the process output parameter i.e., surface roughness during AWJM of DRCUFP composites. From main effects plot for means for surface roughness (Fig. 15) the optimum cutting conditions for minimum surface roughness can be established at, water pressure (A): 300 bar, traverse speed (B): $50 \mathrm{~mm}$, stand of distance: $1 \mathrm{~mm}$, abrasive flow rate: $12 \mathrm{~g} / \mathrm{s}$, depth of cut (C): $5 \mathrm{~mm}$ and abrasive size: 200 microns. Table 6 shows the response table surface roughness. Table 7 shows thepredicted values of surface roughness using TDOE. Figure 8 shows the SEM image of machined surface.

\subsection{Effect of process parameters on surface roughness using FLM}

Fuzzy logic model has been developed using MATLAB version R2007b mamdani fuzzy expert system. Triangular membership functions are used for input variables and Gaussian membership functions are used for output variable. The rules applied are represented in the form of IF-THEN conditional statements (Ravindra et al., 2018). Figure 17 shows the fuzzy rule editor.

Figure 18 represents the effect of water pressure and traverse speed on surface roughness during AWJM of DRCUFP composites. Initially during machining, surface roughness was very high (3.36 microns) at 100 bar water pressure. As the water pressure increased to 300 bar, surface roughness gradually reduced to 3.26 microns. This is because as the AWJ pressure increases the fibers break down into smaller ones and kinetic energy of the fibers increases which results in smoother machined surface for all the conditions. Traverse speed showed a small variation in surface roughness value this is because at lower traverse speed there is more contact between the abrasive impingement and the workpiece which resulted in smoother finish at $50 \mathrm{~mm} / \mathrm{min}$ traverse speed.

Figure 19 represents the effect of water pressure and stand of distance on surface roughness during AWJM of DRCUFP composites. Initially during machining, surface roughness was very high (3.38 microns) at 100 bar and low at stand of distance $1 \mathrm{~mm}$. As the water pressure increased to 300 bar the surface roughness value improved. But in 


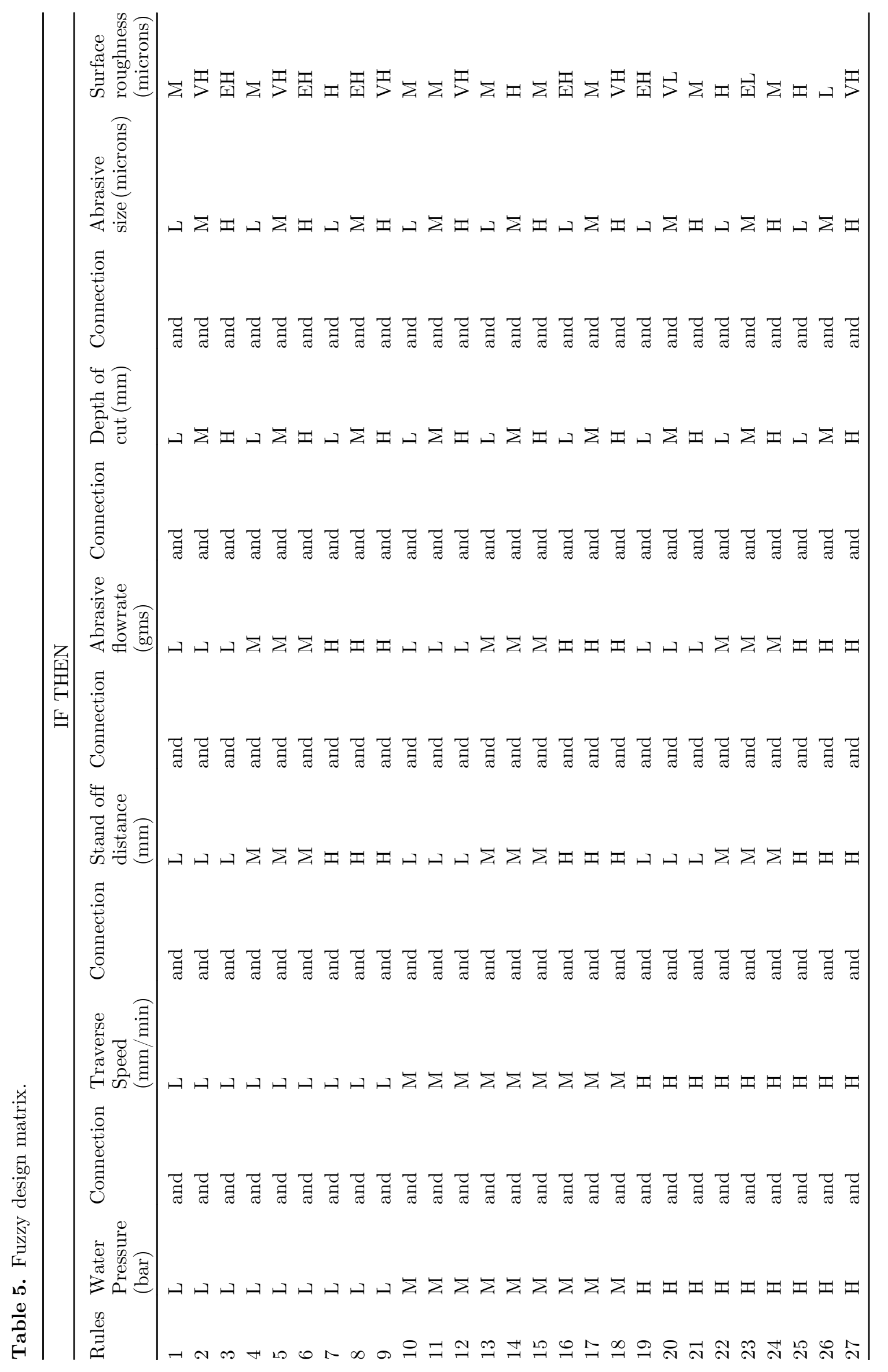




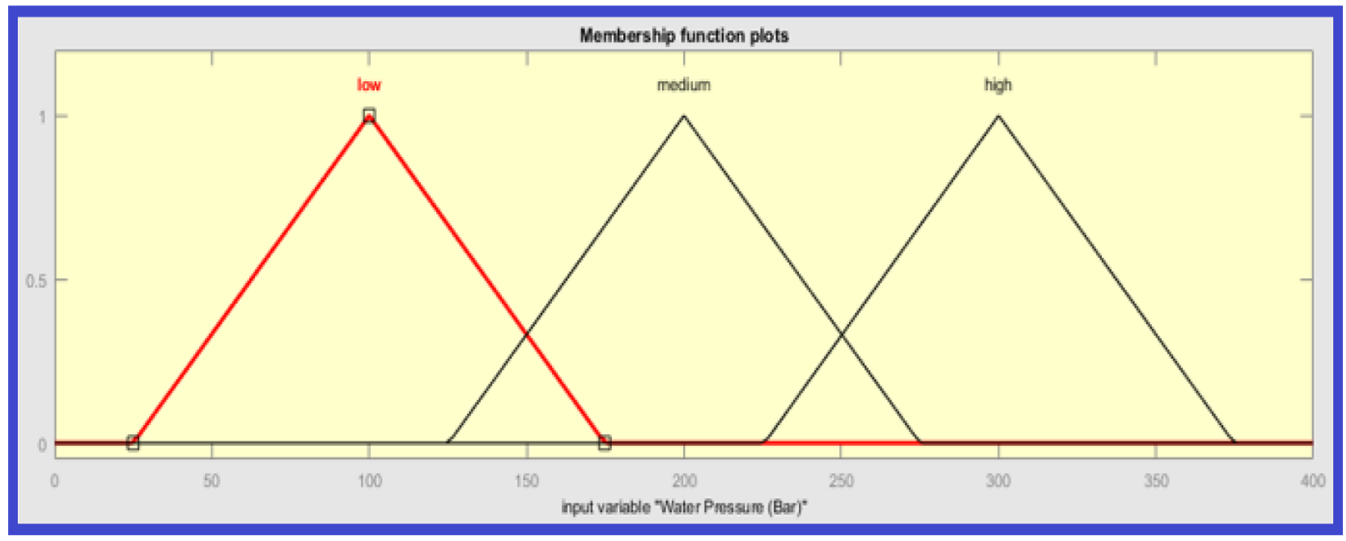

Fig. 8. Fuzzification of Input parameter water pressure (bar).

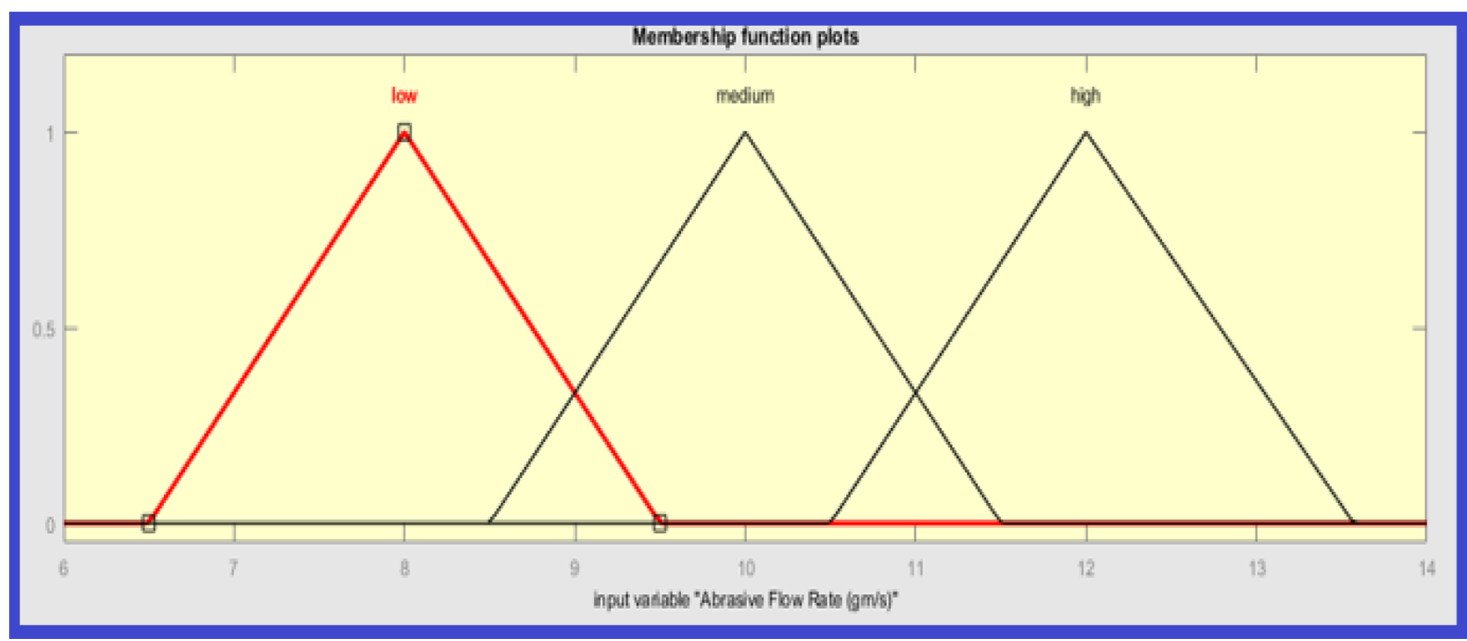

Fig. 9. Fuzzification of Input parameter abrasive flowrate (microns).

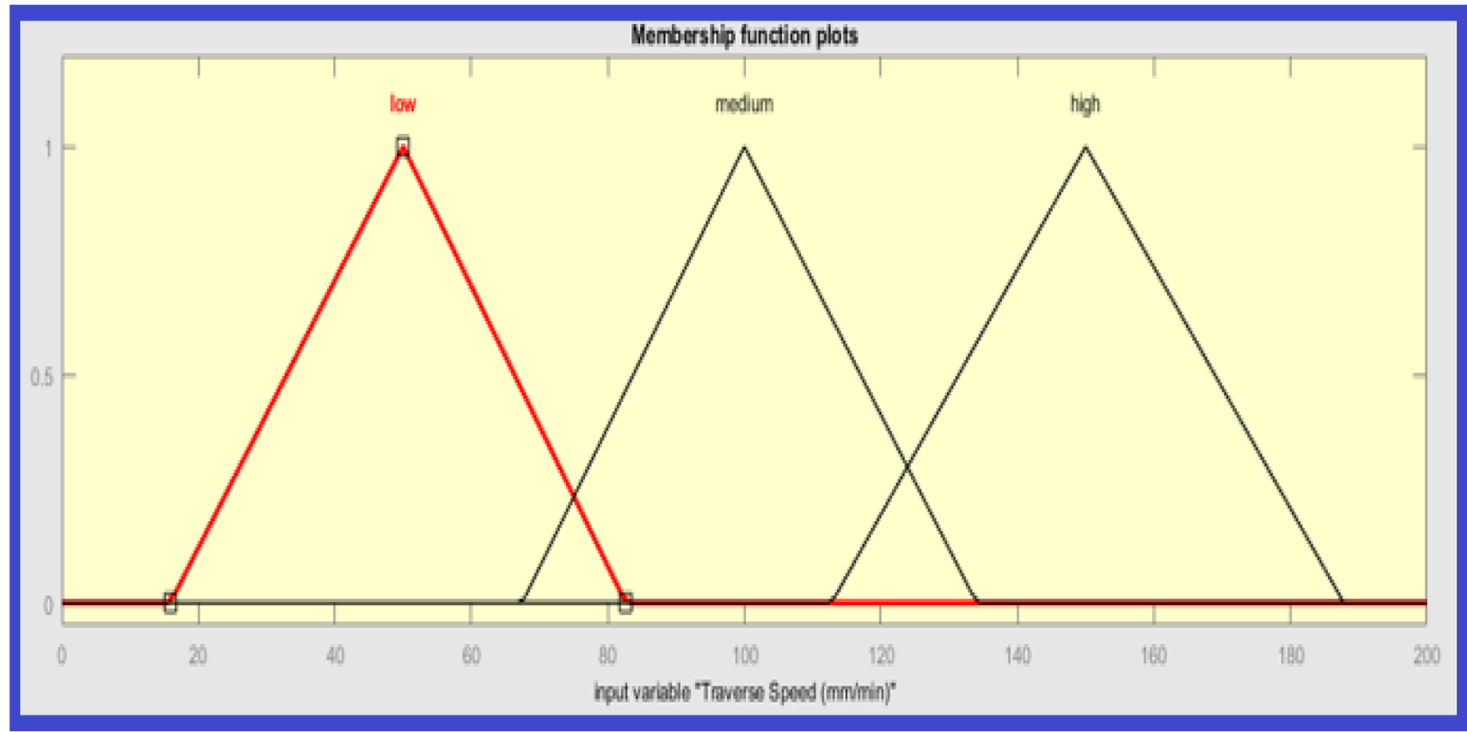

Fig. 10. Fuzzification of Input parameter traverse speed $(\mathrm{mm} / \mathrm{min})$. 
Table 6. Inputs and outputs to fuzzy logic modeling.

\begin{tabular}{llll}
\hline Variable parameters & Input/ Output & Min & Max \\
\hline Water pressure (bar) & Input & 100 & 300 \\
Traverse Speed (mm/min) & Input & 50 & 150 \\
Stand off distance (mm) & Input & 1 & 4 \\
Abrasive flow rate (gm/s) & Input & 8 & 12 \\
Depth of cut (mm) & Input & 5 & 15 \\
Abrasive size (microns) & Input & 100 & 200 \\
Surface Roughness (microns) & Output & 3.1 & 3.5 \\
\hline
\end{tabular}

Table 7. Response table surface roughness.

\begin{tabular}{lllllll}
\hline $\begin{array}{l}\text { Water } \\
\text { pressure } \\
(\text { Bar })\end{array}$ & $\begin{array}{l}\text { Traverse } \\
\text { speed } \\
(\mathrm{mm} / \mathrm{min})\end{array}$ & $\begin{array}{l}\text { Stand of } \\
\text { distance } \\
(\mathrm{mm})\end{array}$ & $\begin{array}{l}\text { Abrasive } \\
\text { flow rate } \\
(\mathrm{g} / \mathrm{s})\end{array}$ & $\begin{array}{l}\text { Depth of } \\
\text { cut }(\mathrm{mm})\end{array}$ & $\begin{array}{l}\text { Abrasive size } \\
(\text { microns })\end{array}$ & $\begin{array}{l}\text { Mean surface } \\
\text { roughness } \\
(\text { microns })\end{array}$ \\
\hline 300 & 50 & 1 & 12 & 5 & 200 & 3.131 \\
\hline
\end{tabular}

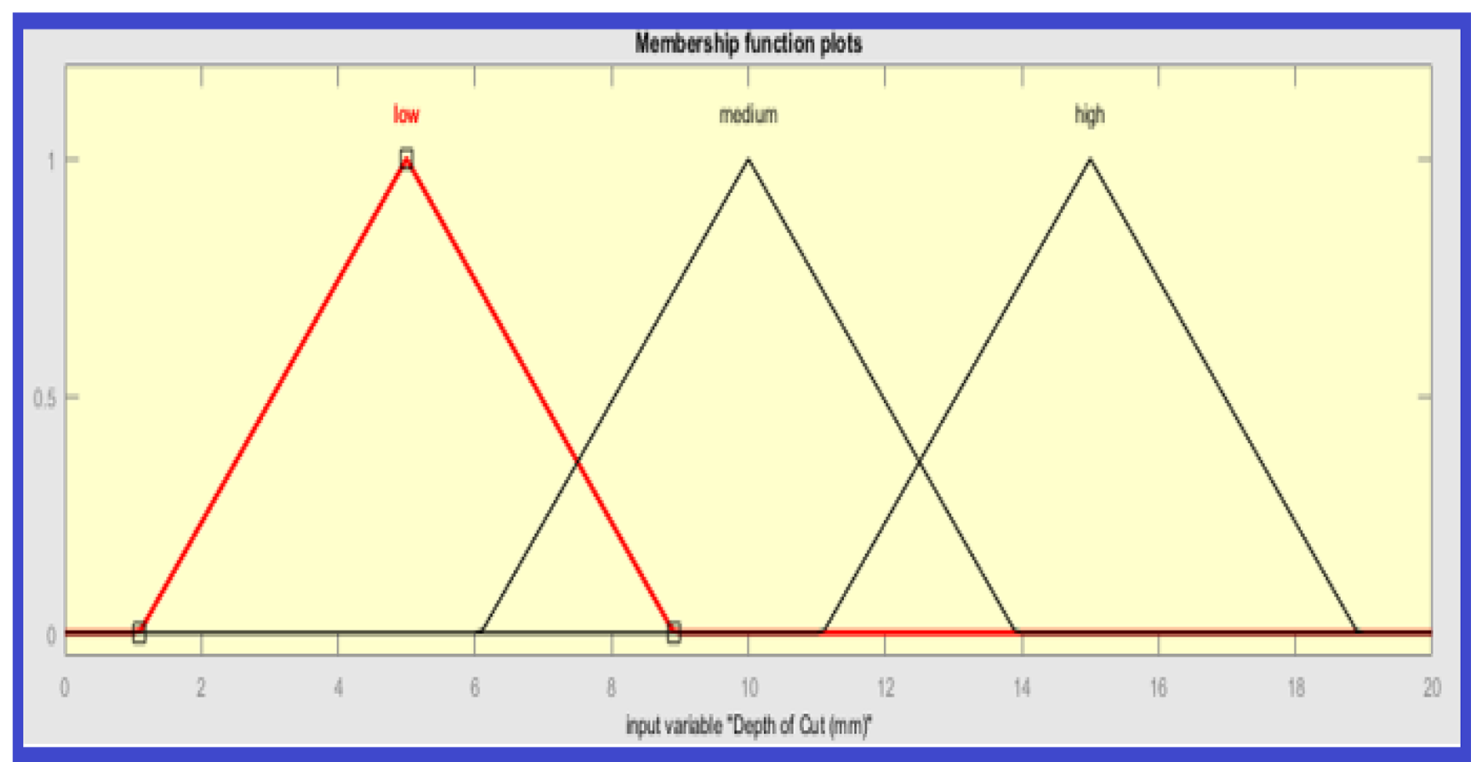

Fig. 11. Fuzzification of Input parameter depth of cut (mm).

Table 8. Predicted values of surface roughness using TDOE.

\begin{tabular}{lllllll}
\hline Level & $\begin{array}{l}\text { Water } \\
\text { pressure } \\
(\text { Bar })\end{array}$ & $\begin{array}{l}\text { Traverse } \\
\text { speed } \\
(\mathrm{mm} / \mathrm{min})\end{array}$ & $\begin{array}{l}\text { Stand of } \\
\text { distance } \\
(\mathrm{mm})\end{array}$ & $\begin{array}{l}\text { Abrasive } \\
\text { flow rate } \\
(\mathrm{g} / \mathrm{s})\end{array}$ & $\begin{array}{l}\text { Depth of } \\
\text { cut }(\mathrm{mm})\end{array}$ & $\begin{array}{l}\text { Abrasive size } \\
(\text { microns })\end{array}$ \\
\hline 1 & 3.369 & 3.286 & 3.307 & 3.325 & 3.241 & 3.316 \\
2 & 3.318 & 3.311 & 3.315 & 3.315 & 3.320 & 3.316 \\
3 & 3.253 & 3.342 & 3.317 & 3.300 & 3.379 & 3.308 \\
Delta & 0.116 & 0.056 & 0.011 & 0.024 & 0.138 & 0.009 \\
Rank & 2 & 3 & 5 & 4 & 1 & 6 \\
\hline
\end{tabular}




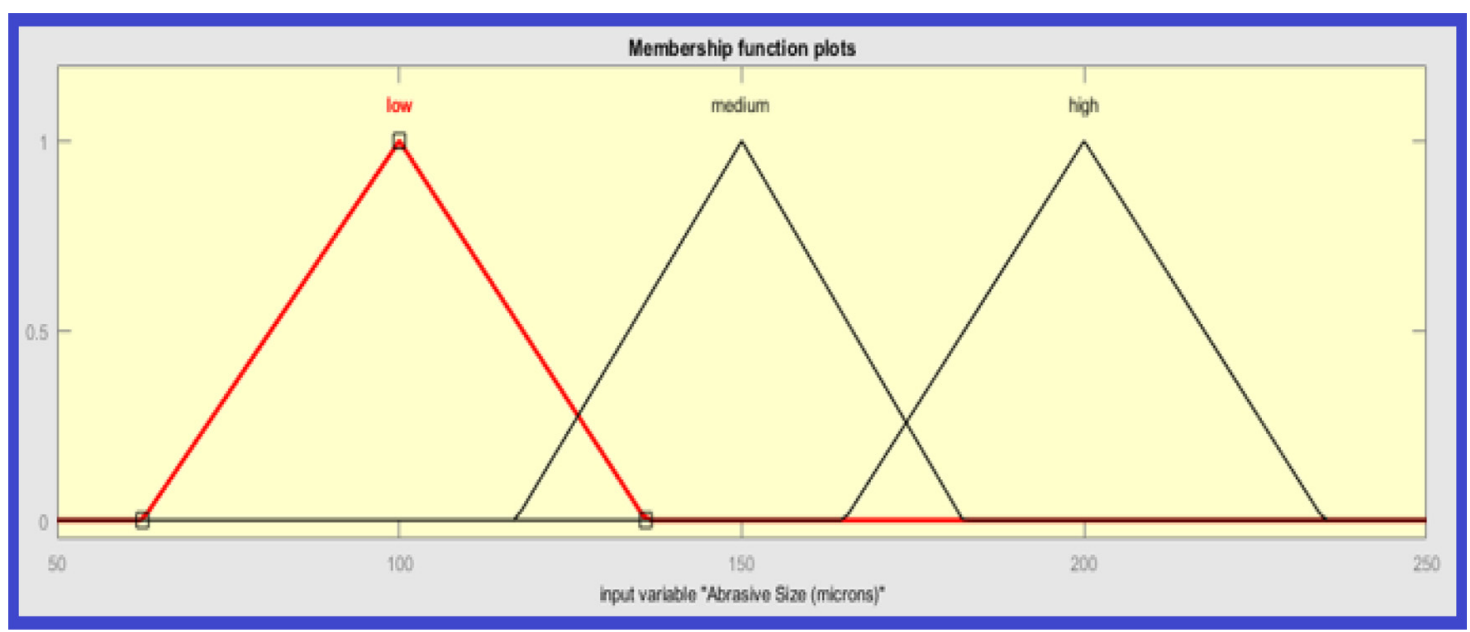

Fig. 12. Fuzzification of Input parameter abrasive size (microns).

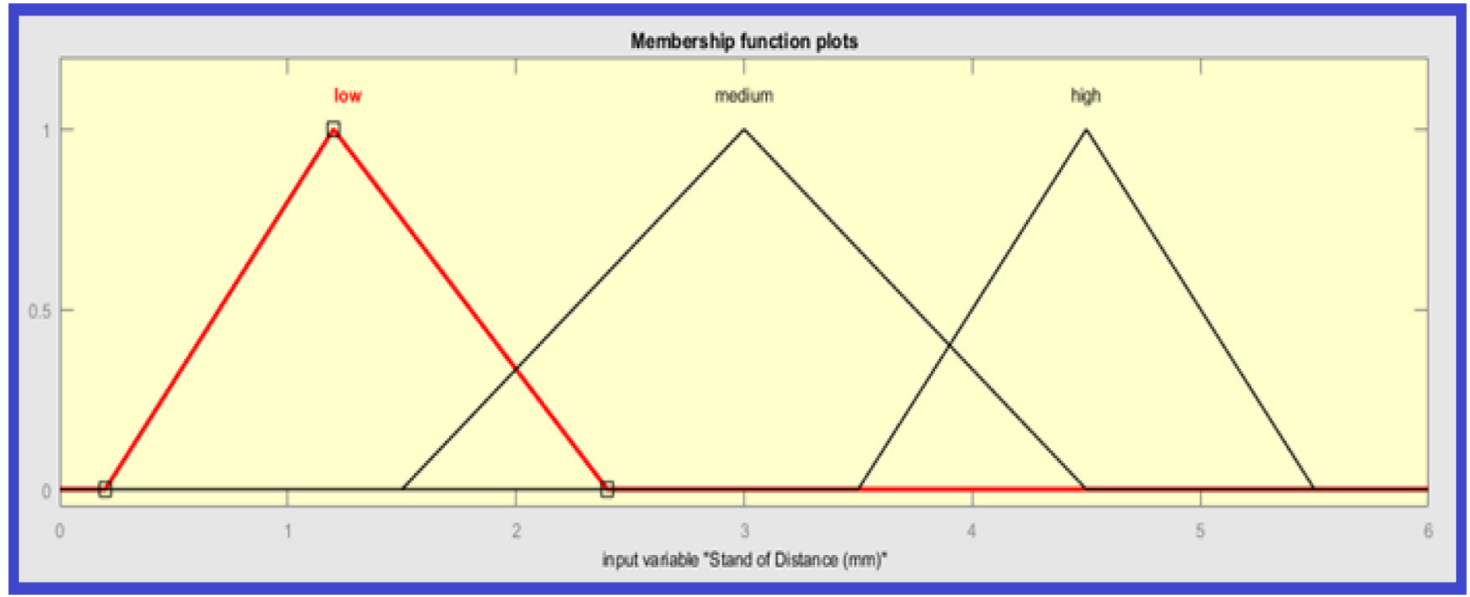

Fig. 13. Fuzzification of Input parameter stand of distance (mm).

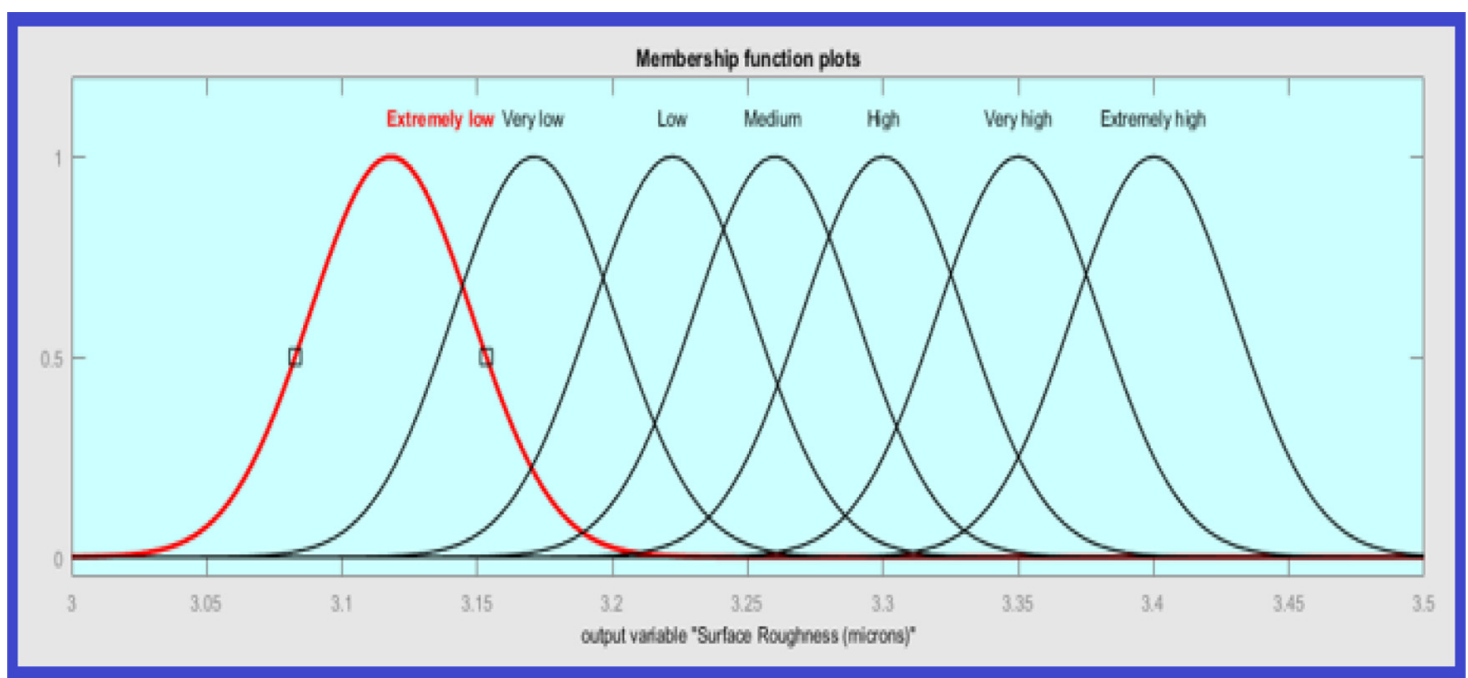

Fig. 14. Fuzzification of output parameter surface roughness (microns). 
Main Effects Plot for Means Data Means

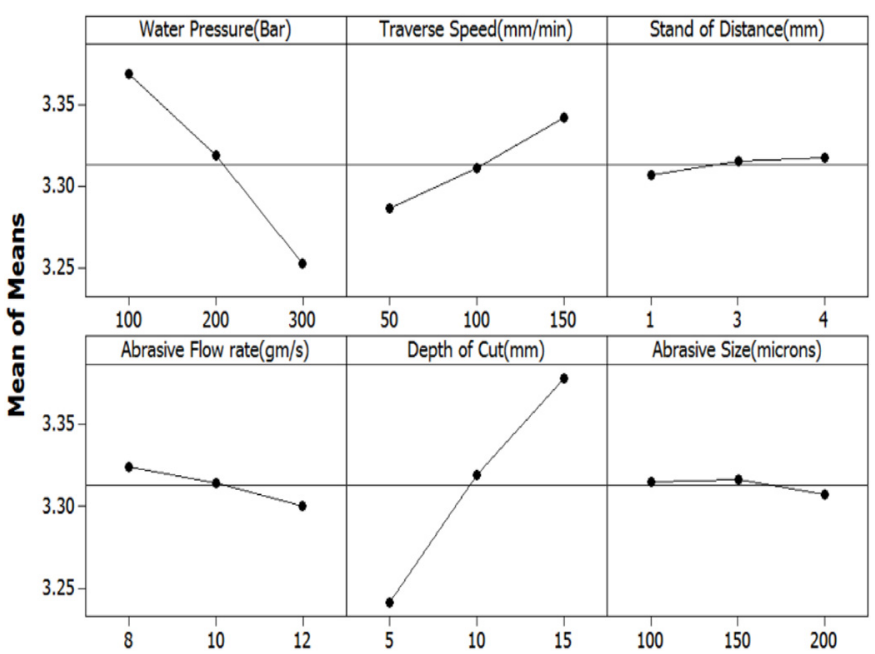

Fig. 15. Main effects plot of output parameter surface roughness (microns).
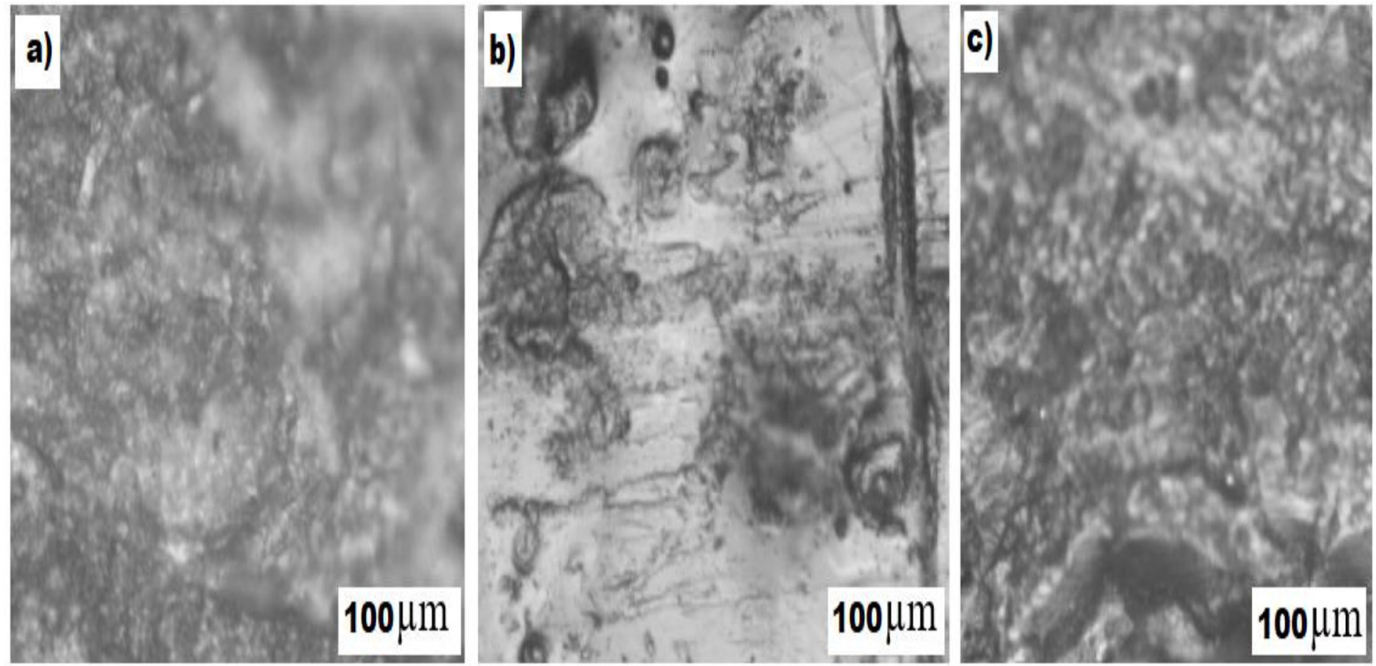

Fig. 16. SEM image of machined surface (a) 100 bar; (b) 200 bar; (c) 300 bar.

Table 9. Minimum and maximum values of input/output parameters.

\begin{tabular}{llll}
\hline Variables & Input/output & Minimum value & Maximum value \\
\hline Water pressure (Bar) & Input & 100 & 300 \\
Traverse Speed (mm/min) & Input & 50 & 150 \\
Stand of distance (mm) & Input & 1 & 4 \\
Abrasive flow rate (g/s) & Input & 8 & 12 \\
Depth of cut (mm) & Input & 5 & 15 \\
Abrasive size (microns) & Input & 100 & 200 \\
Surface roughness (microns) & Output & 3.47 & 3.25 \\
\hline
\end{tabular}




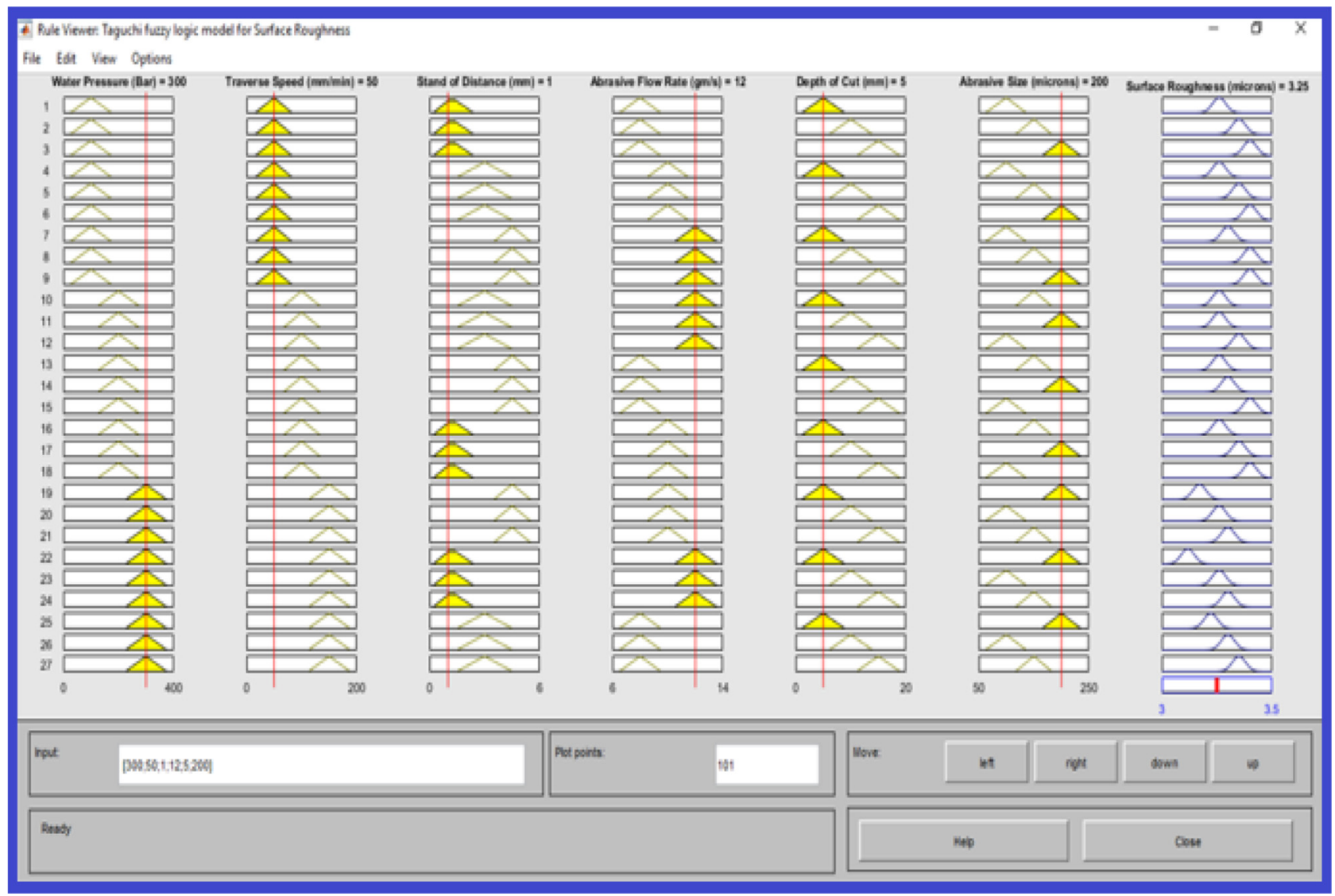

Fig. 17. Fuzzy rule editor.

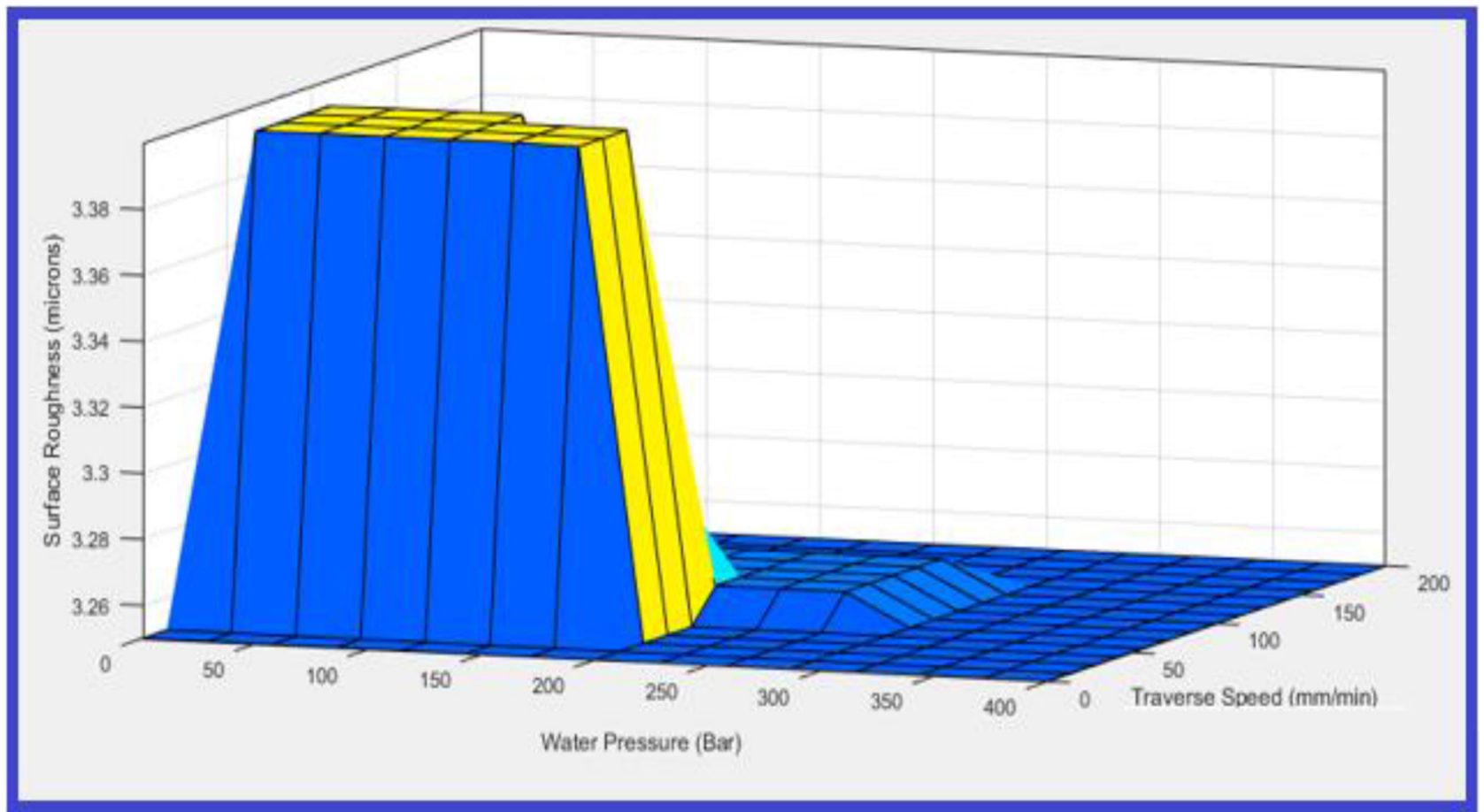

Fig. 18. Effect of water pressure and traverse speed on surface roughness. 


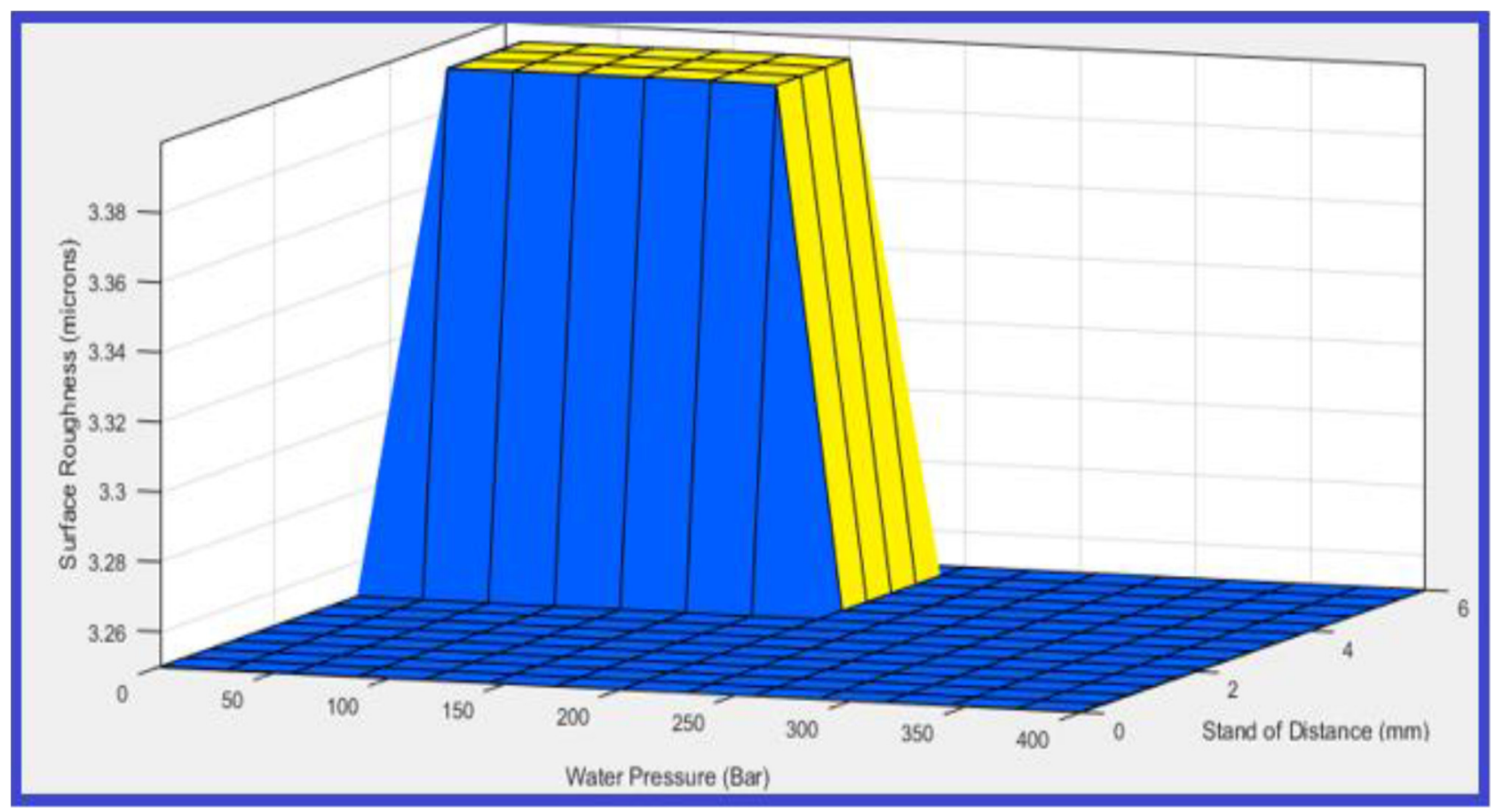

Fig. 19. Effect of water pressure and stand of distance on surface roughness.

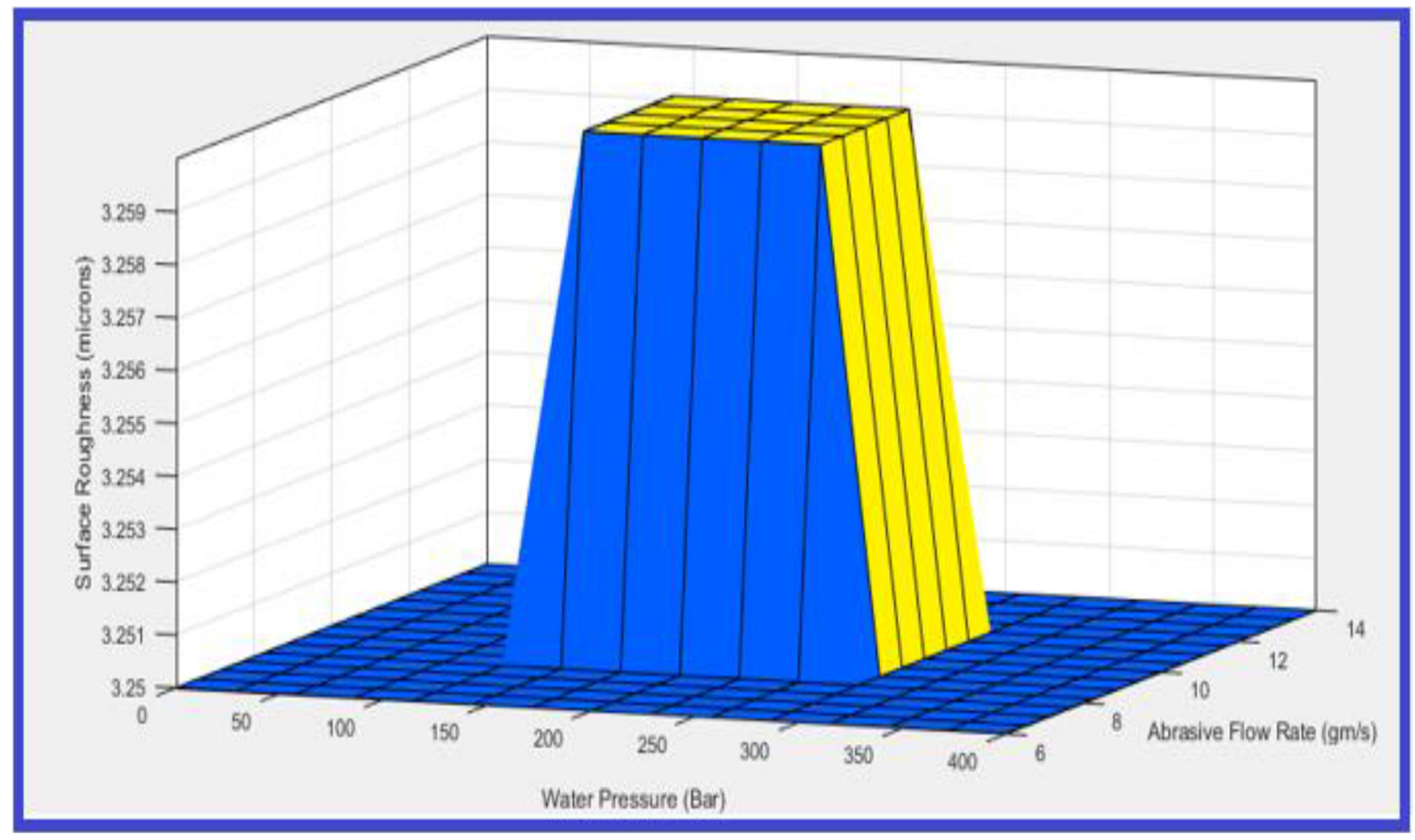

Fig. 20. Effect of water pressure and abrasive flow rate on surface roughness. 


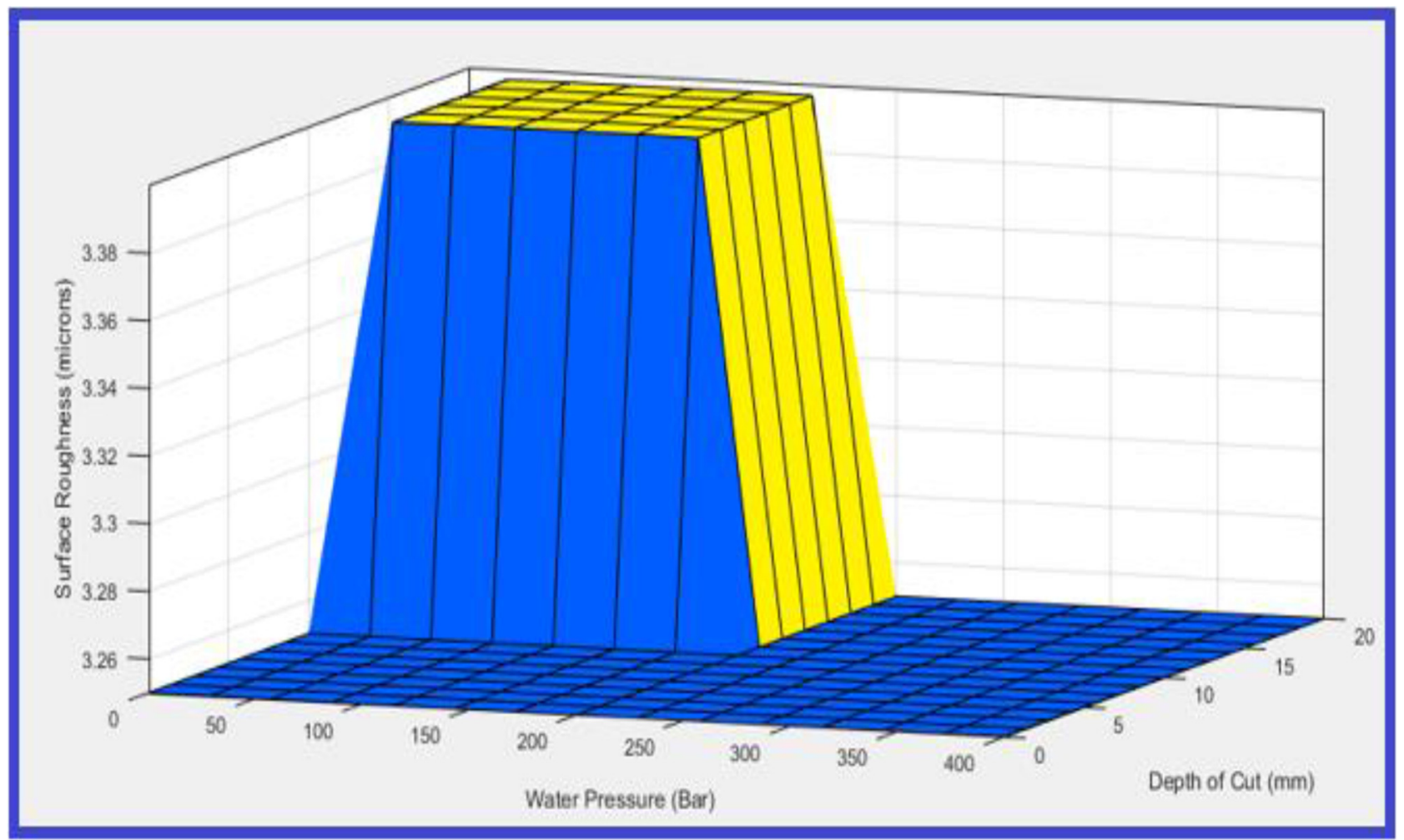

Fig. 21. Effect of water pressure and depth of cut on surface roughness.

case of increase in stand of distance to $4 \mathrm{~mm}$, surface roughness gradually deteriorated to 3.38 microns. This is because at higher stand of distance the jet expands at the nozzle exit which leads for decrease in kinetic energy which results in irregular surface.

Figure 20 represents the effect of water pressure and abrasive flow rate on surface roughness during AWJM of DRCUFP composites. Initially during machining, abrasive flow rate gave a constant surface roughness value (ranging from 3.25 microns to 3.26 microns). This clearly implies that there was no much effect of abrasive flow rate on surface roughness.

Figure 21 represents the effect of water pressure and depth of cut on surface roughness during AWJM of DRCUFP composites. Initially during machining, abrasive flow rate gave a constant surface roughness value (ranging from 3.25 microns to 3.26 microns). This clearly implies that there was no much effect of abrasive flow rate on surface roughness.

Figure 22 represents the effect of water pressure and abrasive size on surface roughness during AWJM of DRCUFP composites. Here during machining, abrasive size gave much variation in surface roughness value (ranging from 3.29 microns to 3.34 microns). This clearly implies that stable jet induced due high energy small particles resulting in secondary cutting operation that improves the surface quality. Whereas, as the particle size increases there is decrease in energy, resulting in scratches on Kerf walls and deteriorates the surface finish.

From the analysis for surface roughness (microns) generated for minimum and maximum values of input/ output parameters for different cutting parameters based on fuzzy rule based model are shown in Table 8 which clearly indicates that at minimum water pressure (A): 100 bar, traverse speed (B): $50 \mathrm{~mm}$, stand of distance: $1 \mathrm{~mm}$, abrasive flow rate: $8 \mathrm{~g} / \mathrm{s}$, depth of cut $(\mathrm{C}): 5 \mathrm{~mm}$ and abrasive size: 100 micronsgave higher surface roughness values (3.47 microns) than that at maximum water pressure (A): 300 bar, traverse speed (B): $150 \mathrm{~mm}$, stand of distance: $4 \mathrm{~mm}$, abrasive flow rate: $12 \mathrm{~g} / \mathrm{s}$, depth of cut (C): $15 \mathrm{~mm}$ and abrasive size: 200 microns the surface roughness values (3.25 microns).

From the comparison plots for TDOE and FLM for surface roughness (Fig. 23) validated for 27 sets of experiments it was observed that TDOE value were almost nearer to the FLM value.

\section{Conclusions}

In this paper Taguchi based fuzzy logic model for optimisation and prediction of surface roughness during AWJM of DRCUFP composites have been investigated. From the analysis of the development and application of the TDOE and FLM following conclusion can be drawn: - From TDOE the optimum cutting conditions for minimum surface roughness can be established at water pressure (A): 300 bar, traverse speed (B): $50 \mathrm{~mm}$, stand of distance: $1 \mathrm{~mm}$, abrasive flow rate: $12 \mathrm{~g} / \mathrm{s}$, depth of cut (C): $5 \mathrm{~mm}$ and abrasive size: 200 microns.

- From FLM it is observed that minimum water pressure (A): 100 bar, traverse speed (B): $50 \mathrm{~mm}$, stand of distance: $1 \mathrm{~mm}$, abrasive flow rate: $8 \mathrm{~g} / \mathrm{s}$, depth of cut $(\mathrm{C}): 5 \mathrm{~mm}$ and 


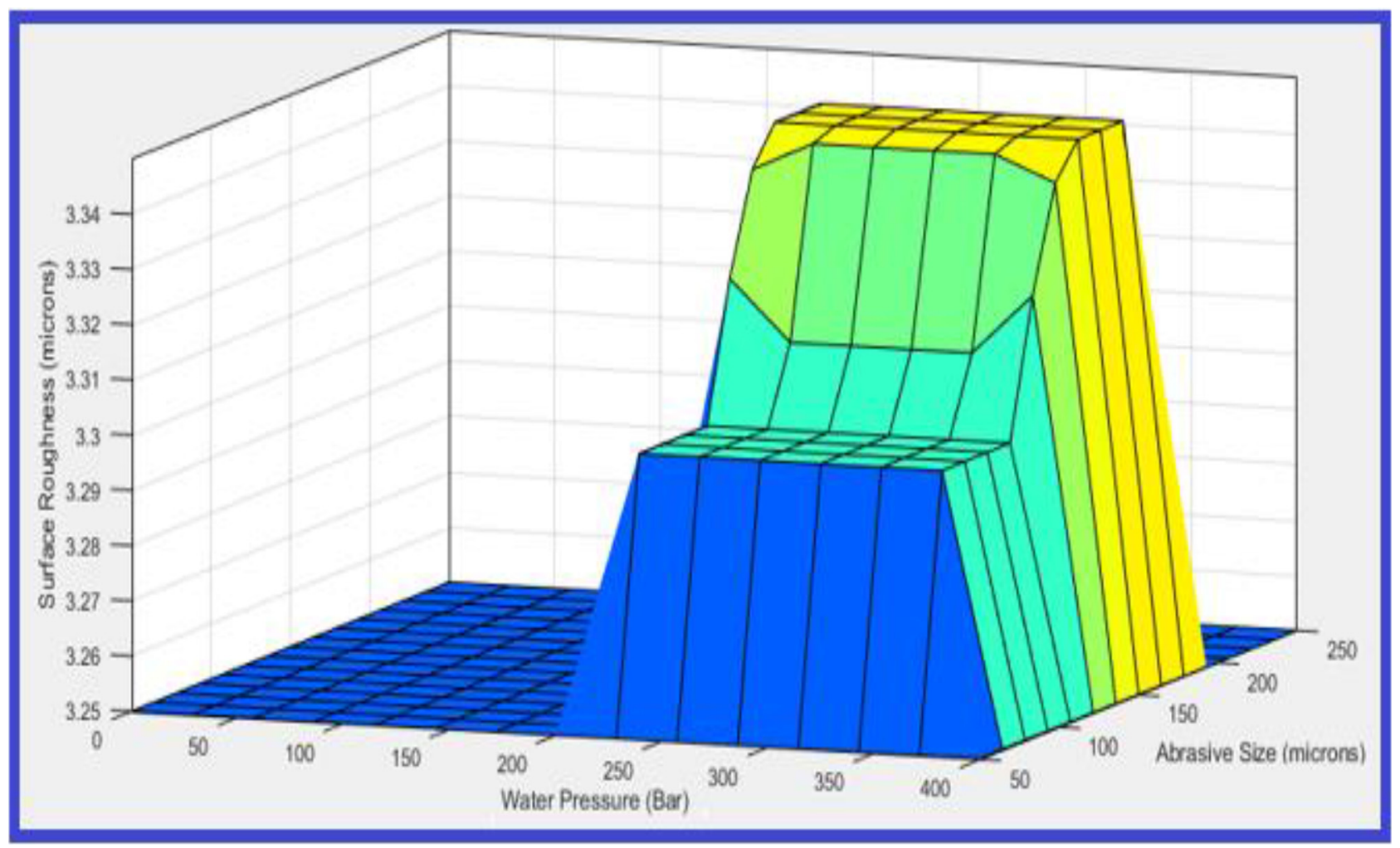

Fig. 22. Effect of water pressure and abrasive size on surface roughness.

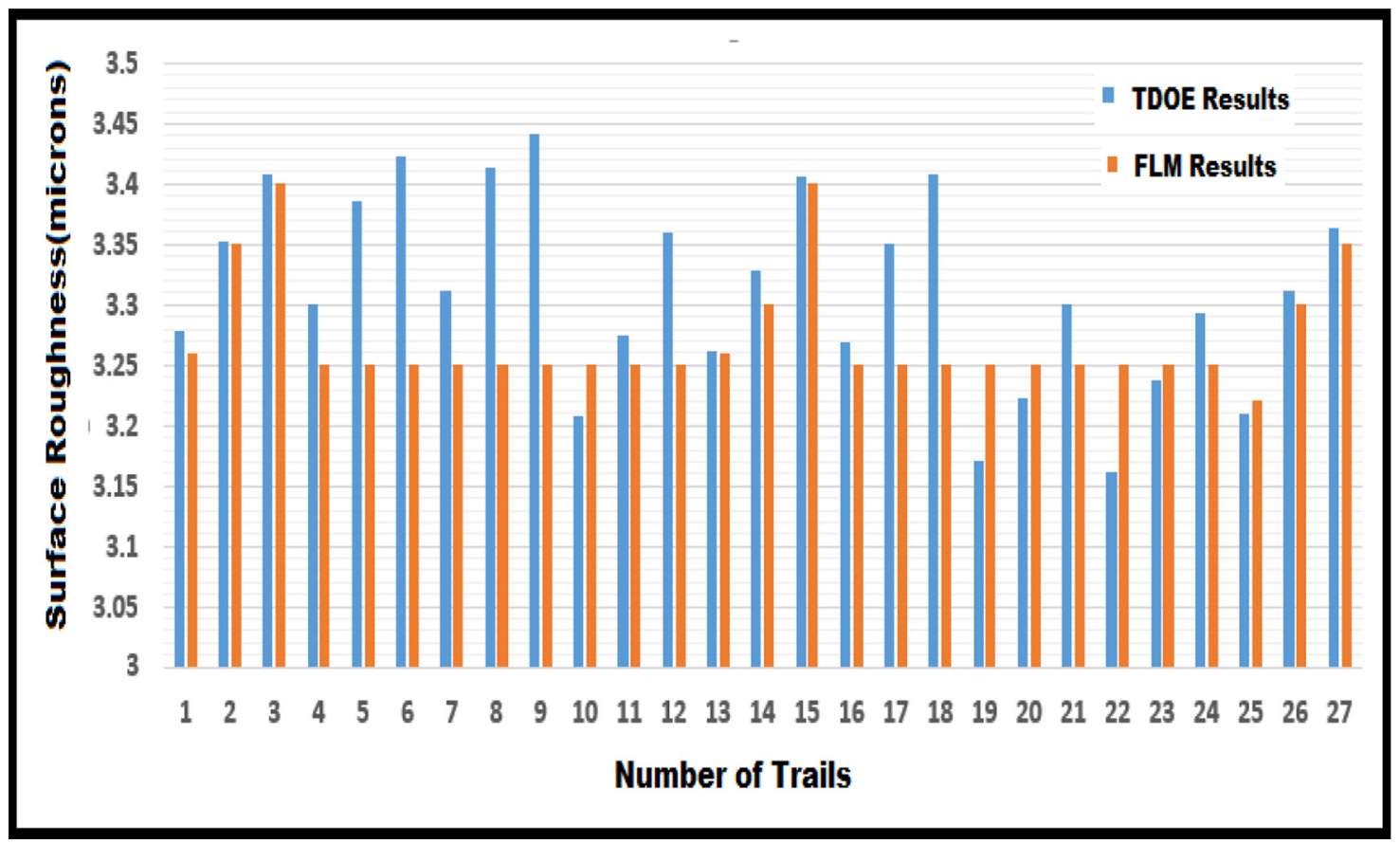

Fig. 23. Comparison plots for TDOE and FLM for surface roughness (microns). 
abrasive size: 100 microns gave higher surface roughness values (3.47 microns) than that at maximum water pressure (A): 300 bar, traverse speed (B): $150 \mathrm{~mm}$, stand of distance: $4 \mathrm{~mm}$, abrasive flow rate: $12 \mathrm{~g} / \mathrm{s}$, depth of cut (C): $15 \mathrm{~mm}$ and abrasive size: 200 microns the surface roughness values (3.25 microns).

- From the comparison plots for TDOE and FLM for surface roughness validated for 27 sets of experiments it was observed that TDOE value were almost nearer to the FLM value.

- In addition, DRCUFP composites are sustainable and could be fully recyclable, but could be more expensive if fully natural based and biodegradable and they are extremely sensitive to moisture and temperature. If a proper matrix is used, DRCUFP composites could be $100 \%$ biodegradable.

\section{References}

1. K. Pickering, Properties and Performance of Natural-Fibre Composites, CRC Press LLC, Boca Raton, 2008

2. C. Baley, F. Busnel, Y. Grohens, O. Sire, Influence of chemical treatments on surface properties and adhesion of flax fibre-polyester resin, Compos. Part A: Appl. Sci. Manufactur. 37 (2006) 1626-1637

3. D.B. Dittenber, H.V.S. GangaRao, Critical review of recent publications on use of natural composites in infrastructure, Composites Part A 43 (2012) 1419-1429

4. R. Joffe, J. Andersons, L. Wallström, Strength and adhesion characteristics of elementary flax fibres with different surface treatments, Composites Part A 34 (2003) 603-612

5. A.K. Bledzki, V.E. Sperber, O. Faruk, Natural and wood fibre reinforcement in polymers, Rapra Review Reports. 13 (2002) 1

6. J.L. Broge, Natural fibers in automotive components, Automot. Eng. Int. 108 (2000) 120

7. C. Clemons, Wood-plastic Composites in the United States: The interfacing of two Industries., For. Prod. J. 52 (2002) 10-18

8. M. Karus, M. Kaup, S. Ortmann, Use of natural fibres in the German and Austrian automotive industry. Market survey, Status, analysis and trends. Nova-Institute $\mathrm{GmbH}$, Hürth, Germany. (2002)

9. P. Kandachar, R. Brouwer, Applications of Bio-Composites in Industrial Products. , Mater. Res. Soc. Symp. Proc. 702 (2002) 101-112

10. J. Biagiotti, D. Puglia, J.M. Kenny, A review on natural fibre-based composites - Part I: Structure, processing and properties of vegetable fibres, J. Natl. Fibers 1 (2004) $37-68$

11. H.L. Bos, K. Molenveld, W. Teunissen, A.M. Van Wingerde, D.R.V. Van Delft, Compressive behaviour of unidirectional flax fibre reinforced composites, J. Mater. Sci. 39 (2004) 2159-2168

12. H.L. Bos, M. Van Den Oever, O. Peters, Tensile and compressive properties of flax fibres for natural fibre reinforced composites, J. Mater. Sci. 37 (2002) 1683-1692

13. S. Chapple, R. Anandjiwala, Flammability of natural fiber-reinforced composites and strategies for fire retardancy: a review, J. Thermoplast. Compos. Mater. (2010) $871-893$
14. C. Gourier, A. Le Duigou, A. Bourmaud, C. Baley, Mechanical analysis of elementary flax fibre tensile properties after different thermal cycles, Composites Part A 64 (2014) 159-166

15. M. Hughes, J. Carpenter, C. Hill, Deformation and fracture behaviour of flax fibre reinforced thermosetting polymer matrix composites, J. Mater. Sci. 42 (2007) 2499-2511

16. R. Joffe, J. Andersons, L. Wallström, Strength and adhesion characteristics of elementary flax fibres with different surface treatments, Composites Part A 34 (2003) 603-612

17. P. Wambua, J. Ivens, I. Verpoest, Natural fibres: can they replace glass in fibre reinforced plastics? Compos. Sci. Technol. 63 (2003) 1259-1264

18. L. Yan, N. Chouw, K. Jayaraman, Flax fibre and its composites - a review, Compos. Part B 56 (2014) 296-317

19. M. Ramesh, K. Palanikumar, K.H. Reddy, Mechanical property evaluation of sisal-jute-glass fiber reinforced polyester composites, Composites Part B 48 (2013) 1-9

20. R. Shetty, R. Pai, A.B.V. Barboza, V. Pankaj Kumar Gandhi, Processing, mechanical charaterization and its tribological study of discontinously reinforced caryota urens fibre polyester composites, ARPN J. Eng. Appl. Sci. 13 (2018) 3920-3928

21. R. Shetty, R. Nayak, A.B.V. Barboza, Mechanical and machinability study of discontinuously reinforced sisal fiber polyester composites, Mater. Res. Express 6 (2019) 105370

22. R. Shetty, R. Pai, S.S. Rao, V. Kamath, Machinability study on discontinuously reinforced aluminium composites (DRACs) using response surface methodology and Taguchi's design of experiments under dry cutting condition, Maejo Int. J. Sci. Technol. 2 (2008) 227-239

23. R. Shetty, R.B. Pai, S.S. Rao, R. Nayak, Taguchi's technique in machining of metal matrix composites', J. Br. Soc. Mech. Sci. Eng. 31 (2009) 12-20

24. G.D. Revankar, R. Shetty, S.S. Rao, V.N. Gaitonde, Selection of optimal process parameters in Ball Burnishing of Titanium Alloy, Mach. Sci. Technol. 18 (2014) 464-483

25. A. Momber, R. Kovacevic, Principles of Abrasive Waterjet Machining. Springer-Verlag, London, 1998

26. J.O. Obiko, F.M. Mwema, M. Oluwatosin Bodunrin, Validation and optimization of cutting parameters for Ti6Al-4V turning operation using DEFORM 3D simulations and Tagucci method, Manufactur. Rev. 8 (2021) 5

27. J.O. Obiko, C. Obara, F.M. Mwema, J.N. Keraita, H. Shagwira, A multi-response optimization of the multidirectional forging process for aluminium 7075 alloy using grey-based taguchi method, SN Appl. Sci. Spri. Inter. 3 (2021) 1-20

28. M. Poovalingam, Multi objective optimization of wear behaviour of Aluminum MMCs using Grey-Taguchi method, Manufacturing Rev. 7 (2020) 16

29. S.K. Choudhary, R.S. Jadoun, Optimization of EDM process parameters for MRR of Inconel 600 using Taguchi method, Int. J. Mech. Prod. Eng. Res. Dev. 10 (2020) 11481-11492

30. P.B. Patole, V.V. Kulkarni, Optimization of Process Parameters based on Surface Roughness and Cutting Force in MQL Turning of AISI 4340 using Nano Fluid, Mater. Today: Proc. 5 (2018) 104-112

31. M. Chithirai Pon Selvan, N. Mohana Sundara Raju, Assessment of process parameters in abrasive waterjet cutting of stainless steel, Int. J. Adv. Eng. Technol. 1 (2011) 34-40 
32. M. Chithirai Pon Selvan, N. Mohana Sundara Raju, Effects of process parameters on depth of cut in abrasive waterjet cutting of cast iron, Int. J. Sci. Eng. Res. 2 (2011) 1-5

33. P.P. Shirpurkar, S.R. Bobde, V.V. Patil, B.N. Kale, Optimization of turning process parameters by using tool inserts - a review, Int. J. Eng. Innov. Technol. 2 (2012) 216-223
34. R. Malagi Ravindra, S.R. Chougula, R. Shetty, Prediction of cutting force in turning of Ti-6Al-4V under minimum quantity lubrication (MQL) using response surface model and fuzzy logic model, Int. J. Mech. Product. Eng. Res. Dev. 8 (2018) 263-274

Cite this article as: Raviraj Shetty, Adithya Hegde, Taguchi based fuzzy logic model for optimisation and prediction of surface roughness during AWJM of DRCUFP composites, Manufacturing Rev. 9, 2 (2022) 